\title{
P53 expression in colonic carcinoma - immunohistochemical study
}

\author{
Dena A. Jerjees, Bedoor A. AL- Irhayim \\ Department of Pathology, College of Medicine, University of Mosul.
}

(Ann. Coll. Med. Mosul 2009; 35(2): 111-116).

Received: $20^{\text {th }}$ Oct 2009; Accepted: $24^{\text {th }}$ Mar 2010.

\begin{abstract}
Objectives: To evaluate p53 protein expression in colorectal tumors in Mosul city and correlates it with various clinicopathological parameters and to compare the results with other studies.

Patients and methods: This is a pro and retrospective study of 53 samples of adenocarcinoma of colon with age range from 5 to 80 years. There were 38 males, with age range (5 to 80) years and 15 females with age range (18 to 70 ) years. The samples were collected from Al-Jumhuri Teaching Hospital, Nineveh Private Hospital and private labs during the period from September 2007 through May 2008. P53 protein was detected immunohistochemically by using the primary antibody (monoclonal antibody clone (DO-71) and ${ }^{\mathrm{T} M} \mathrm{G} / 2$ visualizing system/AP, Rabbit/Mouse (permanent red). Positive and negative controls were included in each run. The interpretation was done by a semi quantitative method.
\end{abstract}

Results and conclusions: P53 protein expression was found in 49\% (26 cases) of colorectal cancer. There was no correlation of p53 expression with age, sex, site, and size, but was significantly correlated with grade and stage ( $p$ value $=0.001,0.044$, respectively). By stepwise backward multiple logistic regression the grade was the only independent factor ( $p$ value $=0.033$ ).

Keywords: P53, colonic adenocarcinoma.

الخلاصة

الأهداف: لتقييم إظهار بروتين p53 في أورام القولون في مدينة الموصل و الربط بينها وبين مختلف الصفات المرضية

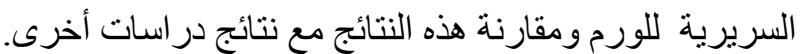

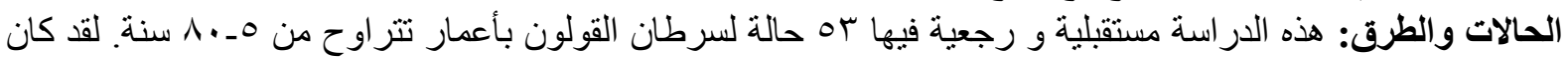

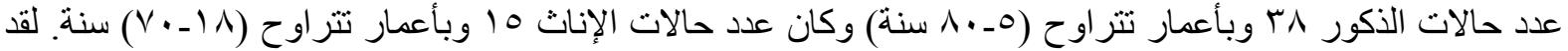

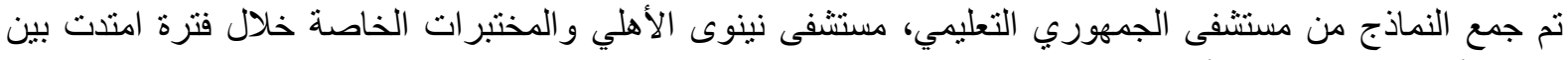

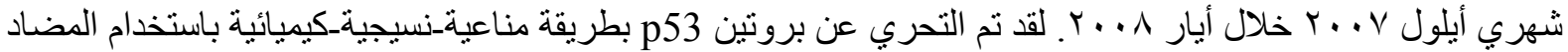

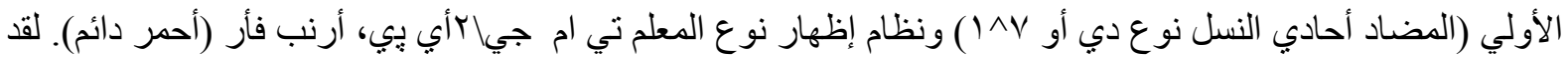

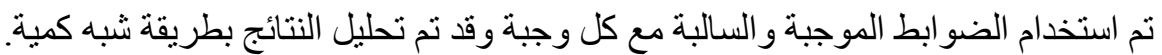

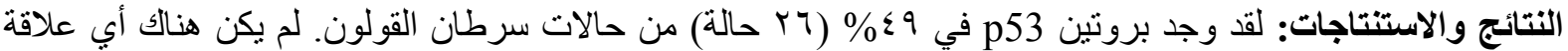

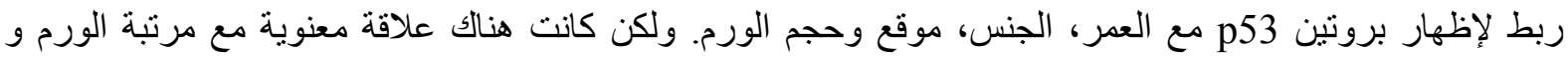

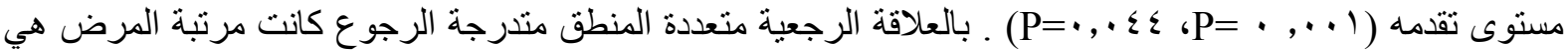

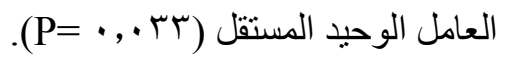


G uardian of the genome"(1),"Death star" (2), " Good and bad cop" (3), are just a few of the names that have been attributed to the p53 gene ${ }^{(4)}$, the mammalian p53 family has 3 members: $p 53, p 63$, and $p 73^{(5)}$. Studies in the late 1970s revealed that a cellular phosphoprotein with a relative molecular mass of about 53000 formed a tight complex with SV40T antigen, and hence the p53 protein was so named ${ }^{(5)}$.

There are two types of p53 protein: normal or wild type and mutant type. The wild type is located in the nucleus, and it functions primarily by controlling the transcription of several other genes. It has a short half life of only 20 minutes ${ }^{(6)}$.

Wild type p53 is believed to play a role in the regulation of cell proliferation and acts as a tumor suppressor by the following mechanism: when DNA is damaged by irradiation, U.V. light or mutagenic chemicals, wild p53 protein levels increase in the cell ${ }^{(7)}$. The accumulated wild p53 binds to DNA, stimulates transcription of several genes, and mediates two major effects on the cell ${ }^{(7)}$. One effect is cell cycle arrest in G1 phase which allows damaged DNA to repair. If the DNA repair has occurred successfully, the level of wild p53 decreases with the help of MDM2 gene product. Then cells which are formed later will be normal ${ }^{(7)}$. The other effect is that: If DNA damage cannot be successfully repaired, p53 guides cells to die by apoptosis by the help of death genes (e.g. BAX) (7). If DNA damage is not successfully repaired and cell did not die, mutations become fixed in the dividing cells and malignant transformation occurs ${ }^{(7)}$.

\section{Patients and methods}

This is a pro and retrospective study of 53 samples of adeno-carcinoma of the colon. The samples were collected from Al-Jumhuri Teaching Hospital, Nineveh Private Hospital and private laboratories during the period from September 2007 through May 2008. There was no follow up of the patients. The patient's age and sex were retrieved from the biopsies request forms. Hematoxylin and eosin stained sections were reviewed for the cases to assess their types and grades.
The size of the tumor was taken as the maximum diameter of the tumor in centimeters. The cases were staged according to Dukes' staging system (8). The p53 expression was assessed immunohistochemically on formalin fixed paraffin embedded tissues of the tumor, using mouse monoclonal antibody isotype clone DO-71 (Dako) and the Envision ${ }^{\mathrm{TM}} \mathrm{G} \mid 2$ system / AP, Rabbit / Mouse (permanent red).

\section{Immunohistochemical staining interpretation}

The interpretation was done by a semiquantitative method, 1000 tumor cells were counted in a high power field to assess the percentage of tumor cells expressing the mutant p53 protein. If $\geq 10 \%$ of tumor cells express the mutant p53 protein they were considered positive; if $<10 \%$ of tumor cells express the protein they were considered negative ${ }^{(9)}$, irrespective of the intensity.

\section{Statistical analysis}

The relation between p53 expression and the clinicopathological variables was analysed by the Chi-square test, Observed/Expected Chisquare test, Fisher Freeman Halton test ${ }^{(8)}$ and Stepwise backward multiple logistic regression (10). The results were considered statistically significant if the $p$ value was $\leq 0.05$.

\section{Results}

There were 38 males and 15 females, the male to female ratio was $2.5: 1$ and the patients' age ranged from 5 to 80 years.

P53 expression was found in $49 \%$ of the cases of adenocarcinoma of the colon with no significant correlation to age ( $p$ value 0.16 ); sex ( $p$ value 0.150$)$; site whether in colon or rectum ( $p$ value 0.900 ); or size ( $p$ value 0.631 ).

Concerning the grade, the relation of p53 expression was significant in using Fisher Freeman Halton test, $p$ value was 0.001 and the peak of p53 expression was in grade 2, i.e. (moderately differentiated).

In relation to stage, the p53 expression showed a significant correlation by using Fisher Freeman Halton test and the $p$ value was 0.044 . The distribution of p53 expression according to Dukes stage is shown in figure (1), most of the cases were of Dukes' B and C. 


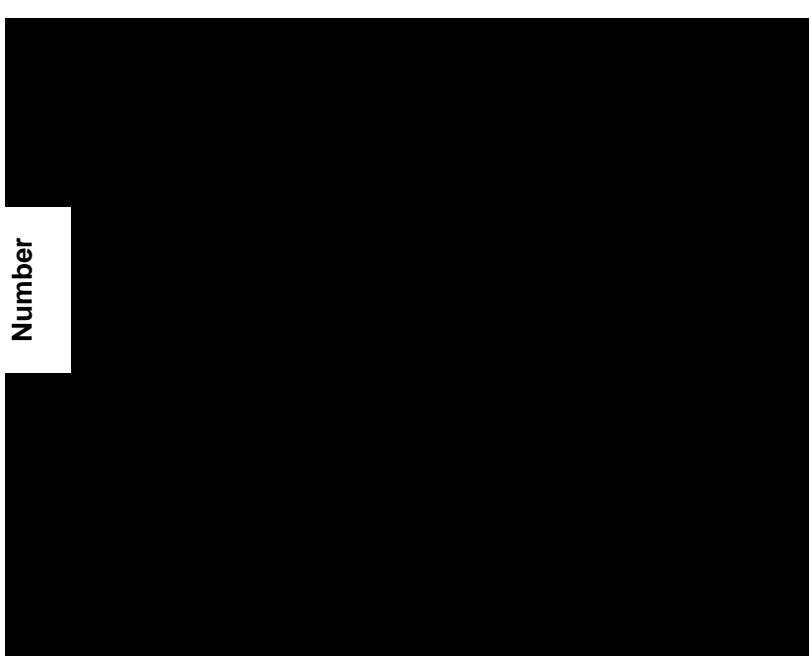

Figure (1): $\mathrm{P} 53+/-$ in colorectal carcinoma (colectomy) cases versus stage.

Table (1): Stepwise backward multiple logistic regression.

\begin{tabular}{|l|c|c|c|}
\hline $\begin{array}{c}\text { Independent } \\
\text { parameter }\end{array}$ & $\mathrm{B}$ & OR & $\mathrm{p}$-value \\
\hline Grade & -1.579 & 0.033 & 0.033 \\
\hline Constant & 2.906 & - & - \\
\hline
\end{tabular}

By stepwise backward multiple logistic regression the only independent parameter which has a significant correlation to p53 expression was the grade, (table 1).

Figures (2-9) are photomicrographs of p53 expression in colonic carcinomas.

\section{Practical application of p53 expression}

The value of p53 expression was practically demonstrated in two of our cases, figures (59):

Case (1): male, 75 years old, with invasive moderately differentiated adenocarcinoma of the colon, Dukes' stage $C$.

Case (2): male, 63 years old, with invasive moderately differentiated adenocarcinoma of the rectum, Dukes' stage B.

These two cases had colonoscopic biopsies prior to colectomy. Each biopsy was composed of small fragments of colonic mucosa, with dysplasia. However p53 was overexpressed in both, figures $(5,8)$.

The colectomy specimens of the two cases revealed invasive carcinoma of the colon, figures $(6,7,9)$.

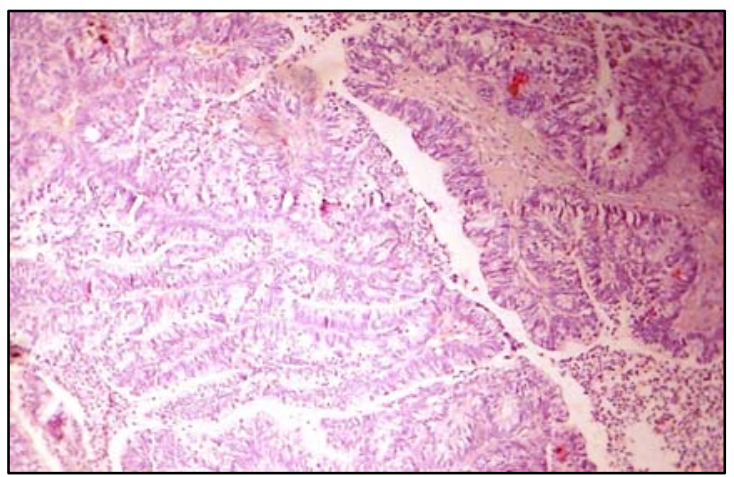

Figure (2): Adenocarcinoma of colon IHC (immunohistichemical) staining negative for p53(original magnification $\times 100$ ).

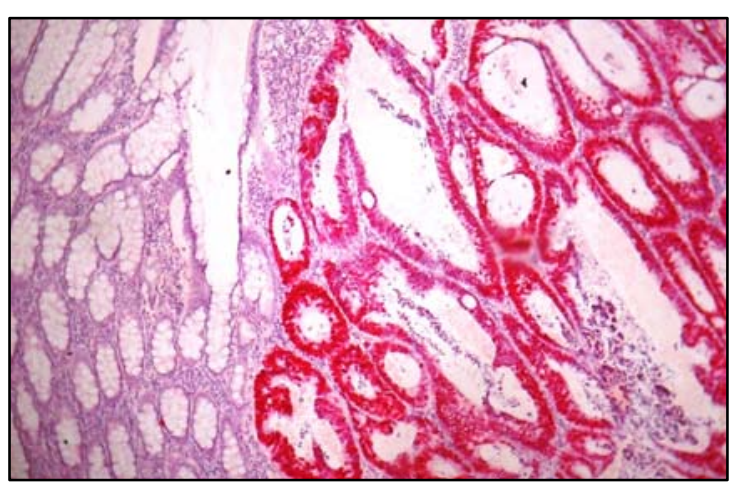

Figure (3): Adenocarcinoma, IHC staining positive for p53, high intensity (original magnification $\times 100$ ).

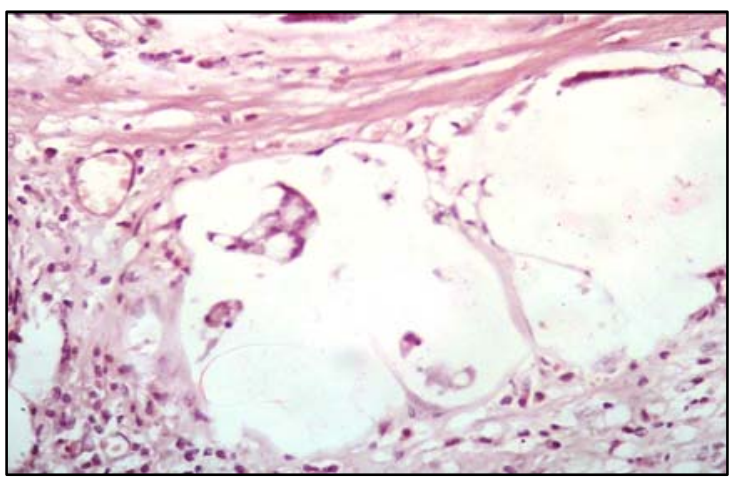

Figure (4): Mucinous carcinoma, IHC staining negative for p53 (original magnification $\times 400$ ). 


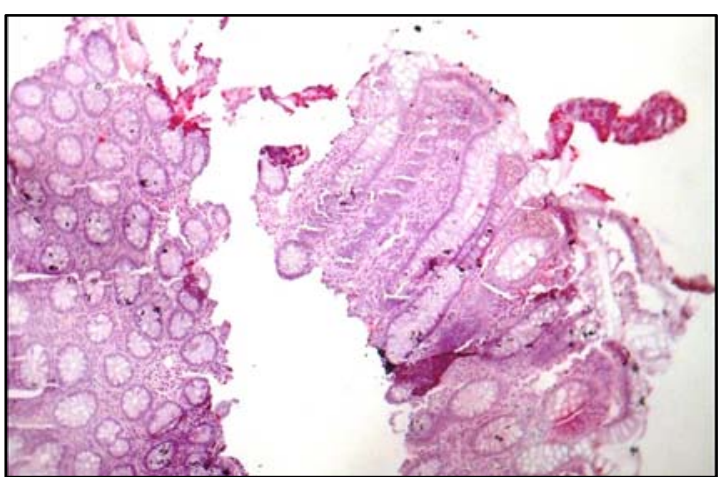

Figure (5): Case study (No.1) /biopsy, with fragment of malignancy, which show positive IHC staining for p53 (original magnification $x$ 100).
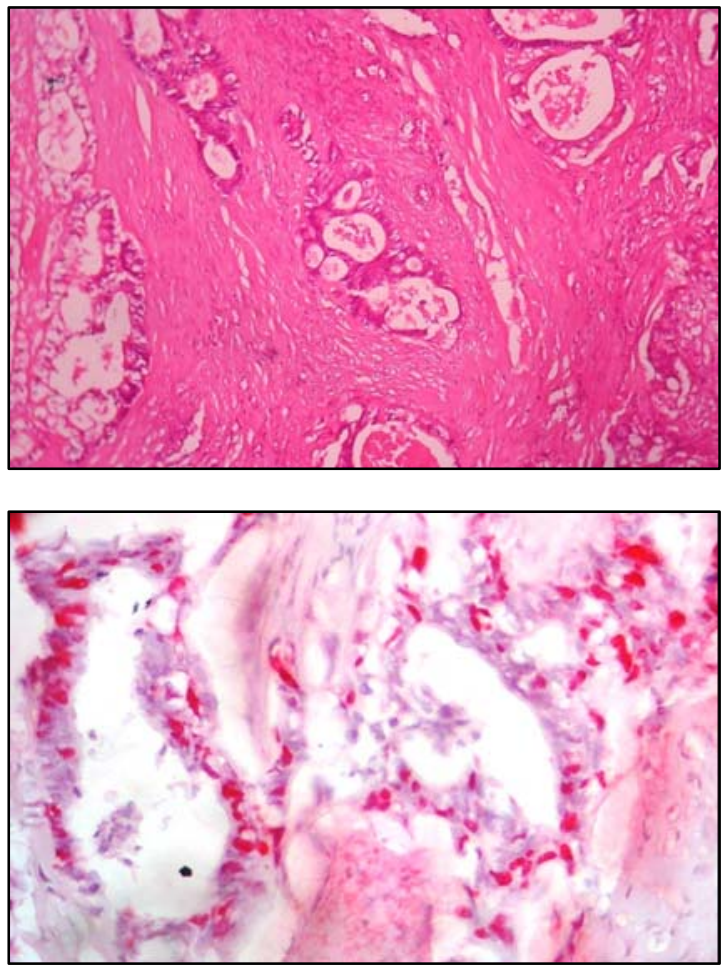

Figures (6,7): Case study (No.1) /colectomy carcinoma, upper: H\&E (original magnification $\times$ 100), lower: IHC positive for p53 (original magnification $\times 400$ ).

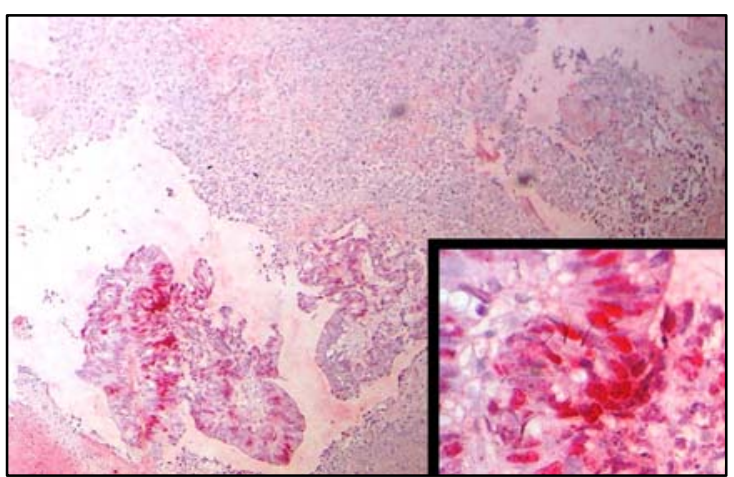

Figure (8): Case study (No.2) /biopsy, carcinoma of the colon, IHC staining positive for p53 (original magnification $\times 100$, the small box $\times 400)$.

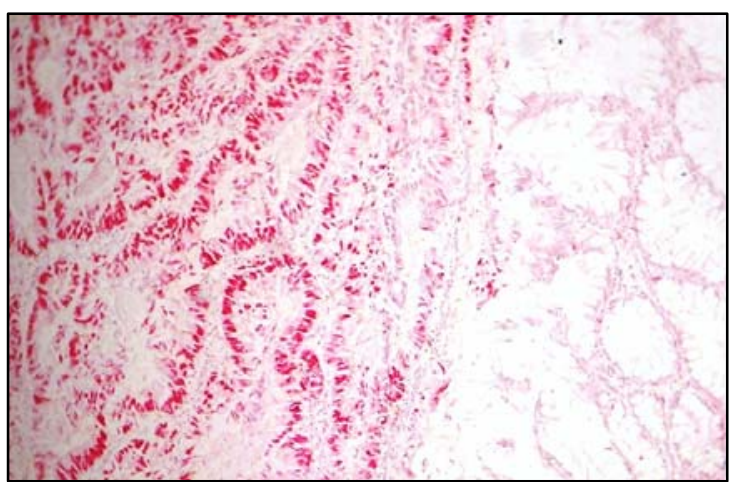

Figure (9): Case study (No.2) /colectomycarcinoma, IHC staining positive for p53 (original magnification $\times 100$ ).

\section{Discussion}

The etiology of colorectal cancer is complex involving an interplay of environmental and genetic factors (11). Colorectal carcinoma develops through a multistep process as characterized by histopathologic precursor lesions and molecular genetic alterations ${ }^{(11)}$. The natural history of colorectal cancers is not necessarily similar, and tumor molecular profile is likely to play an important role in determining the prognosis for individual patients ${ }^{(12,13)}$.

It seems that adjuvant therapy relies on a normal p53 function to trigger apoptosis so that those cells damaged by chemo or radiotherapy can be destroyed for therapeutic purposes. Several studies have shown that tumor cells with impaired p53 function have 
poor response to adjuvant or neoadjuvant therapy ${ }^{(14)}$.

\section{P53 expression}

In our study p53 was expressed in $49 \%$ of the cases. Other similar studies had shown variable ratios (42\%-82\%).

The age factor was not significant. This is consistent with the results of other studies $(11,15)$

No significant correlation was found with sex. Our result is consistent with other studies ${ }^{(11,16)}$ and is different from a single study that showed a significant correlation with male gender ${ }^{(15)}$.

The correlation with site in this study was not significant contrary to others who reported significant correlation ${ }^{(13,17)}$. The site variation for p53 expression has been attributed to several factors including right versus left colon, effects of sex hormones, diet, as well as genetic causes. It is likely that there are differences in sensitivity and exposure to carcinogens for the proximal and distal sections of colon ${ }^{(18)}$.

The p53 expression in relation to size is not significant and this result is similar to that of Asaad et al ${ }^{(17)}$ and differs from that of Demirbas et al ${ }^{(19)}$.

The p53 expression in relation to grade is significant and this is consistent with three studies ${ }^{(19-21)}$ and different from other studies which had reported no significant correlation $(13,15)$, while an inverse relationship was reported by one study ${ }^{(22)}$.

The expression of p53 protein in relation to stage was significant. A single study ${ }^{(20)}$ also reported a significant correlation of p53 expression with stage while other studies ${ }^{(11,}$ ${ }^{13,17)}$ reported no significant correlation.

Assessment of p53 expression in colonic biopsies is advisable because it may be of help in predicting malignancy especially when there is a degree of dysplasia.

\section{Conclusion}

- p53 expression was found in $49 \%$ of cases, this result is within the range observed by others.

- p53 expression was significantly correlated with tumor grade and stage (positive, negative). The grade of the tumor was the only independent parameter by the stepwise backward multiple logistic regression. All of the 6 cases of mucinous adenocarcinoma were negative for $\mathrm{p} 53$.

- Age, sex, size and site had no significant correlation with p53 expression.

\section{References}

1. Lane D.p, Guardian of the genome. Nature 1992; 358:15-16.

2. Vousden KH. p53. Death star. Cell 2000; 103:691-4.

3. Sharpless NE and Depinho RA. Good cop/Bad cop. Cell 2002; 110: 9-12.

4. Irwin MS and Kaelin WG. p53 family update: p73 and p53 develop their own identities. Cell Growth and Differentiation 2001; 12:337-49.

5. Fearon ER and Vogelstein B (1997). Tumor suppressor gene defects in human cancer. In: Holland JF, Frei E, Bast RC, Eds. Tumor suppressor and DNA repair gene defects in human cancer. Cancer Medicine $4^{\text {th }}$ Edition. Williams and Wilkins, Baltimore; pp.97-117.

6. Mehta KU, Goldfarb MA and Zinterhofer LJ. Absent p53 protein in colorectal tumors reflects poor survival. The Journal of Applied Research 2002; 2:1-15.

7. Oren $M$ and Rotter V. p53: the $1^{\text {st }} 20$ years. Cell Mol Life Science 1999; 55:911.

8. Gervaz $\mathrm{P}$, Bouzourene $\mathrm{H}$, Cerottini JP, et al. Dukes B colorectal cancer: distinct genetic categories and clinical outcome based on proximal or distal tumor location. Dis Colon Rectum 2001; 44:364-72.

9. Einspahr JG, Martinez ME and Jiang R. Associations of Ki-ras Proto-oncogene Mutation and p53 Gene Over expression in Sporadic Colorectal Adenomas with Demographic and Clinicopathologic Characteristics. Cancer Epidemiology Biomarkers and Prevention 2006; 15:1443-50.

10. Usaj SK, Krtolica $\mathrm{K}$ and Cuk V, et al. Prognostic significance of molecular and immunohistochemical markers in colorectal carcinomas. Archives of oncology 2002; 10(1):27-28. 
11. Smith G, Carey FA, Beattie J, et al. Mutations in APC, Kirsten-ras, and p53_alternative genetic pathways to colorectal cancer. PNAS 2002; 99 (14):9433-8.

12. Nasiri MRG, Rezaei E, Ghafarzadegan K. Expression of p53 in Colorectal Carcinoma: Correlation with Clinicopathologic Features. Arch Iranian Med 2007; 10 (1):38-42.

13. Kahlenberg MS, Sullivan JM, Witmer DD, et al. Molecular prognostics in colorectal cancer. Surg Oncol 2003; 12:173-86.

14. Zhuang $X Q$, Yuan $S Z$, Wang $X H$, et al. Oncoprotein expression and inhibition of apoptosis during colorectal tumorigenesis. China Natl J New Gastroenterol 1996; 2 (1):3-5.

15. Liang JT, Huang KC, Cheng YM, Hsu HC, et al. p53 ove rexpression predicts poor chemosensitivity to high-dose 5fluorouracil plus leucovorin chemotherapy for stage IV colorectal cancers after palliative bowel resection. Int $\mathrm{J}$ Cancer. 2002; 97:451 7.

16. Lanza G, Gafa R and Matteuzzi M, et al. Medullary-Type Poorly Differentiated Adenocarcinoma of the Large Bowel: A Distinct Clinicopathologic Entity Characterized by Microsatellite Instability and Improved Survival. Journal of Clinical Oncology 1999;17:2429.
17. Asaad NY, Kandil MA and Mokhtar NM. Prognostic value of cycline D1 and p53 protein in colorectal carcinoma. Journal of the Egyptians Nat.Cancer Inst 2000; 12(4):283-92.

18. Matsuda $\mathrm{K}$, Masaki $\mathrm{T}$ and Watanbe $\mathrm{T}$. Clinical Significance of MUC1 and MUC2 Mucin and p53 Protein Expression in Colorectal Carcinoma. Japanese Journal of Clinical Oncology 2000; 30: 89-94.

19. Demirbas S, Sucullu I, Yilirim S, et al. Influence of the c-erb B-2, nm23, bcl-2 and p53 protein markers on colorectal cancer. Turk J Gastroenterol 2006; 17(1): 13-19.

20. Popat S, Chen Z, Zhao D, et al. A prospective, blinded analysis of thymidylate synthase and p53 expression as prognostic markers in the adjuvant treatment of colorectal cancer. Annals of Oncology 2006; 17(12):1810-17.

21. Lyall MS, Dundas SR, Curran S. Profiling Markers of Prognosis in Colorectal Cancer. Clinical Cancer Research 2006; 12:1184-91.

22. Georgescu CV, Saftoiu A, Georgescu CC. Correlations of Proliferation Markers, p53 Expression and Histological Findings in Colorectal Carcinom. J Gastrointestin Liver Dis 2007; 16(2):133-39. 